\title{
OBJETIVIDAD Y SUBJETIVIDAD, FORMA Y CONTENIDO EN LA NARRACIÓN FILOSÓFICA DE FERNANDO INCIARTE
}

\author{
Lourdes Flamarique \\ Universidad de Navarra
}

\begin{abstract}
Resumen: ¿'Tiene sentido hablar de objetividad en una narración filosófica? ¿Cabe pensar que precisamente este género literario sirve para alcanzar la inmediatez y verdad propias de la metafisica? En este trabajo se trata de marcar algunos de los jalones que delimitan el intrincado bucle de verdad, objetividad y subjetividad que constituye el hilo argumental del libro Cultura y verdad de Fernando Inciarte, publicado póstumamente. Tomando pie de las claves de lectura dadas por el propio autor, se examina qué tipo de verdad está en juego y si la forma y el estilo narrativo son idóneos para presentarla.
\end{abstract}

Palabras clave: Inciarte, objetividad, subjetividad, verdad práctica, ficción filosófica.

\section{Objectivity and Subjectivity, Form and Content in the philosophical Narration of Fernando Inciarte}

Abstract: Does it make sense to speak of objectivity in philosophical narration? Is it possible to think that precisely this literary genre serves to achieve the immediacy and truth proper to metaphysics? This paper tries to remark some of the milestones that delimit the intricate loop of truth, objectivity and subjectivity that constitutes the plot line of the book Culture and truth of Fernando Inciarte, published posthumously. Taking the reading keys given by the author himself, 
the article analyses what kind of truth is sought, and if the form, the narrative style is suitable to present it.

Keywords: Inciarte, Objectiviy, Subjektivity, Pratical Truth, Philosophical Fiction.

Recibido: 28/3/2017 Aceptado: 10/6/2017

En lo que al pensamiento se refiere, el nuevo siglo parece querer distanciarse de las tendencias de moda heredadas, que bajo distintas denominaciones descalificaban la verdad, la realidad, la justicia, la razón, esto es, los conceptos filosóficos fundamentales, como ilusiones sin más, mentiras o mistificaciones siempre al servicio de alguna forma de poder. Frente a esta forma de "Philosophical Correctness", se han levantado voces que, rechazando el escepticismo como actitud primordial, argumentan a favor de una aprehensión veritativa de la realidad. De algún modo, esta reclamación de lo olvidado y traicionado por parte del pensamiento del último siglo, pone contra las cuerdas algunas de sus convicciones más firmes. Por ejemplo, que la verdad dependa solo de procesos lógicos o prácticas de verificación, o que la comunicación sea el resultado de estrategias y sistemas de signos. El ideal de plena transparencia y tolerancia - como las virtudes políticas de la era postideológica - se ha revelado insuficiente ante los nuevos problemas que afrontan los sistemas democráticos; mientras se reconoce la función primordial de la verdad en distintos aspectos de nuestra vida social, política y cultural. Pues, aunque sin esta convicción parece obvio que nuestra cultura científica y filosófica no se sostiene, la "hiper-conciencia" sobre el poder de la mediación conceptual y teórica que la sustenta contribuyó a la proliferación 
de los discursos que desconfiando en nuestra capacidad de verdad la descalificaban como una pretensión "ingenua".

Wittgenstein pensaba que el realismo en filosofía es lo más difícil ${ }^{1}$. Parece que la filosofía se ha puesto de nuevo a la tarea; basta ver las publicaciones recientes para advertir que el término 'realismo' ha sido rehabilitado, rescatado y re-significado para la misma causa que lo acunó, la de la verdad filosófica. No se trata sin más de una vuelta al pasado, de la sustitución de las creencias post-modernas por las pre-modernas. La crítica a la cultura del constructivismo social y mediático vino precedida por fenómenos que fueron interpretados como la búsqueda de lo verdaderamente real: una "necesidad de lo real" debida a que, si antes pensábamos que confundíamos la ficción con la realidad, ahora nos ocurre al revés. "Mucho más difícil que desenmascarar (lo que parece) la realidad como una ficción es reconocer la parte de ficción en la realidad real” (Žižek, 2005: 21). En efecto, tras la exigencia de lo real, estaba la de lo verdadero.

No podía ser de otro modo. Por eso, aun sabiéndose extemporáneos, no pocos pensadores siguieron cultivando en las últimas décadas del pasado siglo, con una firmeza admirable, las preguntas y respuestas de la gran conversación sobre la realidad y la verdad que es la filosofía; por ello, su trabajo fue en parte silenciado y excluido de las tendencias de moda editoriales y mediáticas. Entre ellos, destaca Fernando Inciarte: anticipándose un par de décadas al movimiento "nuevo realismo", defendió el realismo trascendental

1 "Nicht Empiria, und doch Realismus in der Philosophie, das ist das schwerste". Wittgenstein, 1987: 274 . 
y, con él, la posibilidad de la metafísica tras la declaración de su final con todas las armas disponibles, desde las del estilo y exposición más académicos hasta las que presta el arte contemporáneo y los géneros narrativo y de ficción. Inciarte fue un filósofo realista que supo ver la necesaria ficción que sostiene eso que tomamos por realidad, pues la ficción no es el error. Uno de los temas centrales de su trabajo en filosofía, así como de su disposición vital, es el de la verdad. Inciarte se ocupó repetidamente de diferenciar los distintos tipos de verdad, de mostrar sus notas características, abriendo así de nuevo, junto con otros pensadores de su generación, el espacio de la verdad práctica. Y como quien se afana por consolidar las posiciones conquistadas, habitó ese espacio dejando interesantes ejemplos de los caminos por los que se puede dar con la verdad, también con la verdad que comparece no simplemente como resultado del camino cognoscitivo, sino que consiste en el mismo caminar. Este es el caso del escrito que bajo el título Catalanes. Fragmentos de un libro escrito por escribir presentó en Nueva Revista, en agosto de 1998: "Prólogo a Catalanes, un libro escrito por escribir". Sobre la singularidad de los medios que Inciarte utiliza en ese caso para dar con la verdad es suficiente signo que el prólogo sea una composición de varias firmas, un juego de personalidades; en realidad, un monólogo polifónico. La variedad es también una nota que salta a la vista ante los textos que componen los Fragmentos; los que responden al estilo de trabajo científico ya han sido publicados en las colecciones de escritos editados tras su fallecimiento.

La reciente publicación de su parte final, con el título Cultura y verdad (2016), ofrece una base más amplia para apreciar su trabajo. En los dos extensos capítulos Inciarte se sirve de dos categorías técnicas, objetivo y 
subjetivo, a las que trata de extraer su máximo rendimiento hermenéutico, sin abandonar el género narrativo del conjunto. Lo que ensaya en su parte final, vale para el todo; pues, aunque temáticamente aparecen en la tercera parte, en Cultura y verdad, según el propio autor, "es un hecho que subjetivismo y objetivismo (en la vida, en el arte y en la filosofía) constituyen ya el par de coordenadas que estructuran toda la obra monumental" (Inciarte, Nota preliminar, Pro manuscripto).

En este trabajo se trata de marcar algunos de los jalones que delimitan el intrincado bucle de verdad, objetividad y subjetividad que constituye el hilo argumental de este original texto. El propio autor ha dejado unas claves de lectura cuya eficacia pone a prueba en el desarrollo de la narración, consciente de que es preciso dilucidar qué tipo de verdad nos sale al encuentro, y si la forma, el estilo narrativo (y apenas discursivo) es idóneo para presentarla. Si este escrito (el conjunto con cada una de sus partes) fuera una apuesta, diría que lo que Inciarte se juega, la realidad que arriesga, es la vida, la propia vida; no hay otra.

\section{Buscando la objetividad de lo subjetivo, cuando la forma es el contenido y viceversa}

Como indica ya el título de mi trabajo, su tema central es la objetividad solo que vinculada a una forma de escritura que convencionalmente no se considera obligada por el criterio de lo objetivo: la ficción narrativa. Sin embargo, pretendo mostrar que por eso mismo, por su condición narrativa, es filosofía y se sitúa en el conocimiento objetivo; que de esta manera, su autor ensaya de nuevo la ineludible exigencia de inmediatez, de verdad y realidad 
que encontramos en los escritos que sustentan la tradición filosófica. Lo interesante es que la ficción sin máscaras puede ser un medio idóneo para la verdad. De entrada no se concluye que sea el único ni que valga para cualquier problema ${ }^{2}$. Pero la verdad, sea en el modo que sea, implica objetividad. (Como la ciencia, podríamos añadir, implica subjetividad en algún sentido).

Las páginas editadas bajo el título Cultura y verdad no contienen un escrito confesional, un fragmento autobiográfico. No obstante, el autor se confiesa, es decir, se interpreta al hilo de sucesos, encuentros, personas que forman parte de su vida. Si parece dominar la dimensión objetiva sobre la subjetiva, es porque no pierde de vista que solo la lógica propia de la fenomenología de lo subjetivo ofrece las condiciones para la exposición objetiva. La paradoja está servida. Inciarte lleva el contraste al extremo desde el título del primero de sus dos capítulos: "Qué y cómo o sobre el objetivismo y subjetivismo en el arte y su relación con diversas formas de vida”. Enseguida, ya en la primera línea, alerta al lector: "En contra de lo que pudiera sugerir el título, esto va a ser en buena parte una narración” (Inciarte, 2016: 27).

Como se trata de la tercera y última parte de un escrito mayor (que el lector de Cultura y verdad no conoce), "nuestro autor" puede iniciar la conversación, sin presentarse siquiera, utilizando la forma del plural de autoría ("le vamos a llamar") y dando por supuesto que habrá lectores ya familiarizados con la narrativa y con el narrador. Son los que le han acompa-

2 Aunque admiraba la "prosa filosófica" de Proust y Musil, de Newman y Joyce, reconoce que "no es sólo cuestión de prosa", sino del esfuerzo de superación del mundo y de sus pompas, es decir, por aprender a vivir y a morir" (Inciarte, 2001: 191). 
ñado en su viaje por el tiempo pasado del escrito que termina con estos dos capítulos. Se dirige a ellos involucrando su presente de lectores, reclamando una complicidad sin la que el texto, lo narrado, no podría funcionar.

Detrás de la publicación de Cultura y verdad hay una selección, algo que al propio Inciarte no le hubiera sorprendido, pues, como refiere en uno de los prólogos que él mismo escribió a su "obra monumental", dando por perdida la versión manuscrita (aunque parece que no es así), allí dice: "lo que el lector tiene en sus manos no representa mucho más que la mitad del texto total. Se impone, pues, una breve referencia a los criterios de selección”3.

Pues bien, si lo que contiene Cultura y verdad son fragmentos de fragmentos (como sugiere el subtítulo de Catalanes), cabe siguiendo al propio Inciarte, hacer una breve referencia a los criterios de selección y, como él hace, a la vez pensar el género literario, el cómo y el qué de esta obra que le llevó a escribir varios prólogos y adelantar posibles recensiones (Nueva Revista, 1998). Es decir, voy a añadir otra recensión, un prólogo más, con referencias a los anteriores, tal como nuestro autor hizo. Por si esto no fuera

\footnotetext{
3 "Las fases por las que ha pasado en el curso de su elaboración no han podido por menos de dejar huellas en el presente volumen. Pero más que a una carpeta con panfletos dentro, el volumen se parece ahora a un palimpsesto. Las fases principales de elaboración han sido tres: primera, la de la redacción a bolígrafo; segunda, la de la revisión en ordenador; y tercera, la de la reducción final del tamaño. Y de cada una de estas tres fases han quedado restos en los tres distintos niveles de referencias ocasionales a otras páginas dentro del volumen. No tener esto en cuenta podría confundir innecesariamente a un lector concienzudo, por ejemplo a futuros “doctorandos"” (Inciarte, Nota preliminar, Pro manuscripto). La Nota preliminar fue añadida a Catalanes despues de la publicación del Prólogo en Nueva Revista.
} 
ya un motivo para desanimar a posibles lectores, el Prólogo publicado comienza así:

El propósito de esta nota es el de dificultar la lectura del libro. Se trata de evitar que el lector advierta demasiado tarde las nubes que desde el principio se van acumulando bajo un risueño cielo narrativo (Inciarte, 1998: 48).

Estas advertencias no parecen la mejor presentación. De entrada, es una pega que lo escrito no hable por sí sólo. Hace poco leí una frase atribuida a Woddy Allen que funciona como una crítica al texto inciartiano: "las cosas no se dicen, se hacen, porque al hacerlas se dicen solas". Si alguien se pregunta qué sentido tiene escribir para poner dificultades a la lectura, no es mi propósito enmendar a Inciarte facilitando al lector lo que él mismo debe poner de su parte. Sí, en cambio, pretendo dialogar con nuestro autor sobre algo a lo que se refiere repetidamente en los prólogos y recensiones así como en las páginas de Cultura y verdad: la idoneidad de esa forma de escritura, de su forma para el contenido, de su cómo para ese qué.

Pues bien, la primera clave es la idoneidad de la narración, que yo he calificado en la nota editorial de filosófica, atendiendo no a su contenido, sino a su sintaxis. Pero, por más filosófica que se la pretenda, es al fin y al cabo sintaxis narrativa, esto es, literatura. Lo que explica que no sea un demérito que "en todo el relato hasta el final, se da una constante confusión de planos, del plano del pasado narrado y el de la narración presente" (Inciarte, 1998: $50)$.

Y con esto no hago de menos el trabajo de nuestro autor, a quien conocemos sobre todo por su obra "científica", de estricta filosofía. Porque si la 
literatura era y es pensamiento y no meramente una ilustración de ideas o la "ejemplarización" de acciones y conductas, no cabe duda de que en el último siglo, la literatura ha pensado a fondo su tiempo, y precisamente por ello ha mostrado la misma capacidad de transformación que ha caracterizado a la cultura moderna. La literatura — como el arte— ha asumido la tarea reflexiva emprendida por la filosofía, como tema y como método. En su acertada la defensa de la literatura, Barthes la describe como una especie de metaconocimiento, cuyo punto de partida y de llegada es siempre lenguaje. A lo que añado, el lenguaje escrito, escrito incluso cuando remeda la oralidad. Según Barthes, entre la ciencia y la vida hay una enorme distancia que solo puede corregir la literatura. Precisamente porque

...el saber que ella moviliza jamás es ni completo ni final; la literatura no dice que sepa algo sino que sabe de algo, o mejor aún: que ha llegado a saber algo, que alcanza a saber mucho sobre los hombres, lo que conoce de los hombres es lo que podría llamarse la gran argamasa del lenguaje [...]. Como [la literatura] escenifica el lenguaje —en lugar de, simplemente, utilizarlo—, engrana el saber en la rueda de la reflexividad infinita: a través de la escritura el saber reflexiona sin cesar sobre el saber según un discurso que ya no es epistemológico sino dramático (Barthes, 2007: 56).

De eso se trata en Cultura y verdad, podría añadir Inciarte. Porque además acentúa el pathos, el dramatismo de la subjetividad narradora. También estaría de acuerdo con la tesis de Barthes de que la segunda fuerza de la literatura es su fuerza de representación. 
Desde la antigüedad hasta los intentos de la vanguardia, la literatura se afana por representar algo. ¿Qué? Lo diré brutalmente: lo real. Lo real no es representable, y debido a que los hombres quieren sin cesar representarlo con palabras existe una historia de la literatura (Barthes, 2007: 58).

Tal vez por eso, nuestro autor, buen conocedor de la tradición literaria occidental, no tiene conciencia de haber entrado en casa ajena. Así, por ejemplo, cuando en la Nota preliminar da una clave de las partes publicadas como Cultura y verdad (corresponden a Catalanes III), alude a una doble dimensión (temporal y espacial, narrativa y reflexiva, dinámica y estática) que atraviesa todo el texto. $Y$, añade, con razón se insiste

...en la diferencia entre los fenómenos de sucesión y de simultaneidad, correspondientes respectivamente a la dimensiones narrativa y reflexiva del libro. El fenómeno de sucesión corresponde, a su vez, al del tiempo, tan unido a su dimensión narrativa y dinámica. En cambio, el fenómeno de simultaneidad corresponde al del espacio (Inciarte, Nota preliminar, Pro manuscripto).

La doble dimensión (temporal y espacial, narrativa y reflexiva, dinámica y estática) responde a algo tan esencial para la literatura contemporánea como es "la tensión entre lo escrito y el escribir". La escritura es forma arquetípica de comunicación porque rompe como pocas cosas la reserva en la que tratamos de mantener los deseos, anhelos, pensamientos inconfesables, las culpas o los sueños, y a la vez los recompone, en la medida en que abre lo vivido por muy horrendo que sea a la claridad de la palabra común, a una universalidad que libera de la reclusión en lo meramente subjetivo. Piensa Inciarte que en este sentido, "la espacialidad va unida a la dimensión reflexiva, estática o, si 
se quiere, contemplativa del texto, en no menor medida que la temporalidad va unida a su dimensión dinámica y narrativa" (Inciarte, "Nota preliminar", Promanuscripto).

No es extraño que esté tan de moda la literatura sobre la vida: el lenguaje escrito que redime. Life Writting se denomina a ese género en las universidades americanas: se enseña a escribir la propia vida, las enfermedades, experiencias más o menos singulares, y estos libros se sitúan al lado de las obras de los escritores del canon.

Es una variante de esa literatura que trae todo, lo más trivial, contingente, inútil, el libro-suma la denominaba Barthes (suma del saber...), para quien se habían agotado las posibilidades de una representación profunda de la subjetividad. En cierto sentido este escrito se corresponde con el modelo de life writting, Porque lo que nuestro autor escribe es vida intelectual, su vida intelectual, y las idas y venidas, los sueños... Pero en otros aspectos, está lo más lejos posible de ese modelo: pues, aunque desde las primeras líneas Inciarte introduce el plural 'nosotros', 'nuestro hombre', escribe en primera persona ${ }^{4}$.

Si el auge de los escritos autobiográficos parece el producto acabado de una época narcisista porque el autor es su propia creación literaria, ¿cómo afecta que, como en nuestro caso, el autor sea un filósofo? Aunque, en su narración, Inciarte presenta algo distinto a lo que sucede con Sócrates y

\footnotetext{
${ }^{4}$ Inciarte tenía "la sospecha de que, en el caso de este libro, autor, lector y actor probablemente nunca dejarían de coincidir. Sus esfuerzos editoriales parecen haber sido, pues, un caso de $l$ art pour l' art, un caso de trabajo desinteresado", (Inciarte, Nota preliminar, Pro manuscripto).
} 
Platón, alguien pensará que algo así lo ensayó Platón en los diálogos, donde era demasiado permeable la frontera entre el pensamiento del autor y el de Sócrates. La semejanza - si la hubiera - no estaría tanto en la forma como en el tono, a tenor del juicio de R. Llano: "Por su estructura literaria, Catalanes no es socrático. [...] Por otra cosa es Inciarte un filósofo muy socrático: por su ironía” (Llano, 1998: 47).

Platón, al que se refiere varias veces nuestro autor en sus prólogos y recensiones, (¡cómo no!, ya que le dedicó buena parte de su trabajo científico) (Inciarte, 1998), nos enseñó que la filosofía es literaria, literatura: a las ficciones de sus diálogos se suele atribuir, sin discusión, un valor pedagógico. Valor que su discípulo Aristóteles no debía encontrar porque cambia para siempre el género de la literatura conceptual de la que se alimenta la filosofía. Si la escritura es la partida de nacimiento (y de defunción según algunos) de la filosofía, no está decidido qué tipo de escritura, mejor dicho, qué forma literaria es la suya; ni si le corresponde solo una, o dos: Platón versus Aristóteles. La historia de la filosofía compone un canon de sorprendente heterogeneidad estilística. Casi se podría decir que cada una de las obras allí recogidas crea su género, es única: los ya mencionados, pero además, Confesiones, Summa teológica, Discurso del método, Crítica de la razón pura, Fenomenología del espiritu, Temor y temblor, Ser y tiempo, etc.

En los últimos años la cuestión del género literario de la filosofía ha recibido impulso precisamente de quienes guardan la máxima distancia con la filosofía académica, la que configura en torno a las obras aludidas su particular laboratorio. Si como hacen algunos se atribuye al estilo literario la falta de verdad de la filosofía, su pérdida de peso como conocimiento frente a la cien- 
cia, el remedio parece al alcance: basta con presentar las ideas en otro formato. Pero lo más fácil no tiene por qué ser eficaz, y menos adecuado. Admiramos al escritor capaz de crear el lenguaje y la lógica narrativa que coincidan con el objeto narrado. ¿Tiene que ser esto una exigencia de los escritos sobre filosofía? La Crítica de la razón pura la cumple sin duda, pero lo hace El Sofista?

Hay muchos nostálgicos de Platón que sin embargo escriben como seguidores del género aristotélico. Esto es, ensayos argumentativos, expositivos; a veces, escasamente argumentativos no por elección sino por incapacidad. En algunos casos, los autores parecen haber puesto todo su empeño en la originalidad, en dejar al lector un buen rato perplejo, en hacer de su escrito una suerte de acertijo que promete posteridad.

¿De qué es signo esto, si lo es de algo? ¿Me he alejado de la narración inciartiana? No demasiado, como se verá. En su breve ensayo (De escribir ensayos), Hume distingue dos tipos de intelectuales (esto es, los que no están inmersos en la vida animal) que forman la parte elegante de la humanidad: son los eruditos y los conversadores.

Los eruditos son aquéllos que han elegido como destino la dedicación a las operaciones de la mente más elevadas y difíciles, operaciones que requieren tiempo disponible y soledad y que no pueden perfeccionarse sin una larga preparación y duro trabajo (Hume, 2011: 459).

El conversador, en cambio, más sociable, cultiva el entendimiento con ejercicios más fáciles, con reflexiones sobre asuntos humanos y las obligaciones de la vida común, por los defectos o perfecciones de las cosas; nada de 
esto proporciona suficiente ocupación en soledad sino que requieren la compañía y la conversación para poder ser un adecuado ejercicio de la mente. "La separación del mundo erudito y del mundo conversador parece haber sido el gran defecto de la última época” (Hume, 2011: 459). Que el saber sea cultivado por gentes sin gusto por la vida, sin la libertad y facilidad de pensapensamiento y de expresión que solo se alcanza mediante la conversación supone una gran pérdida.

Hume se alegra de que en esta época haya "hombres de letras que han perdido en gran medida aquella timidez y retraimiento que los mantenía distanciados de la humanidad" (Hume, 2011: 460) y que, al mismo tiempo, haya hombres de mundo orgullosos de sacar de los libros sus más agradables temas de conversación. El ensayo es la propuesta de reconciliación, la promesa de un nuevo vínculo entre saber y mundo.

Los escritos publicados en el volumen Cultura y verdad parecen inspirados por el juicio de Hume. Nuestro autor, tras haber dedicado gran parte de la vida a la erudición, habría dejado a un lado su timidez y retraimiento para acercarse a los asuntos más vivenciales, tanto como lo son las propias experiencias vitales. Si como piensa Hume la conversación proporciona una libertad de pensamiento, se entiende que Inciarte adopte el marco de una conversación para sus reflexiones: un 'nosotros', nuestro hombre.

Lo que no excluye que siendo quien es, aclare que como

...[nuestro hombre] ha llegado a construir una teoría que, sin darse él plenamente cuenta de ello, no es más que la elaboración intelectual de su lucha interior, después de una primera parte narrativa (1) nosotros, entre otras cosas, trataremos de exponer, poniéndonos en su lugar, esa teoría y sus posibles deficiencias (2). 
Objetividad y subjetividad

Haremos así honor al título de este trabajo, que aunque al principio no lo parezca, va a resultar al final un trabajo científico, con notas y todo (Inciarte, 2016: 28).

Entonces, ¿cómo debería ser un escrito que pretende hacer aquello que dice? ¿Cabría realmente diferenciar el qué y el cómo? ¿No sucedería, como advierte el lector de Cultura y verdad, que la dialéctica objetivo-subjetivo, cristianismo y cultura es resuelta en la medida en que se ve su indistinción? Resolución del contenido en la forma, se titula uno de los epígrafes (medio en broma medio en serio, en uno de los prólogos al todo de los fragmentos, dice nuestro autor que para la selección ha optado por la forma) ${ }^{5}$.

Coincido con el autor en que el cómo de este libro es su qué y, viceversa, su contenido, su qué reside principalmente en el cómo, en su forma narrativa. La clave de esa simbiosis nos la da también nuestro autor cuando afirma que por "variadas y hasta divertidas que puedan ser las cosas que narra, el relato trata de una sola, de la muerte; de la muerte y de la resurrección" (Inciarte, 1998: 57). Unas veces en el plano de

...la ficción inherente a la vida sin más: muerte y resurrección, pues, ficticias, como cuando fracasamos y salimos regenerados del fracaso, o cuando sufrimos y sacamos fuerzas de flaqueza; o cuando se nos olvida y se nos vuelve a recordar; o

5 “(...) en la tensión entre forma y contenido, el autor opta deliberadamente por la primera, por la materialidad del continente (de la "horma"), a expensas de lo segundo, si es preciso, de lo que podríamos llamar la espiritualidad del contenido". Esta última frase está incompleta en la publicación de Nueva Revista, por lo que no se entiende bien; solo así no resulta contradictoria (Inciarte, 1998: 55). 
cuando somos nosotros mismos los que olvidamos y volvemos a recordar, etc. Otras veces, pocas, el relato trata explícitamente de esa sola cosa, de la muerte, en el plano de la realidad, el cual, fuera de toda ficción, no es otro que el de la muerte real: lo único que en esta vida no tiene nada de ficticio (Inciarte, 1998: 57).

Pero, inmediatamente se corrige, en realidad no trata de la muerte, es más bien una meditatio mortis; es decir, un ejercicio, más que una exposición. Por eso,- - añado yo - el cómo y el qué, la forma y el contenido se reclaman mutuamente. Donde la forma, horma, puede ser lo más espiritual de todo: Lo narrativo más que lo reflexivo, lo subjetivo más que lo objetivo...

Eso se advierte también en que los fragmentos de nuestro autor componen una unidad que no es lógica, no es exactamente discursiva, como se puede colegir del índice. Como tantos libros contemporáneos, la unidad buscada es en todo caso la que se produce en el lector, en el buen lector ${ }^{6}$. Su orden, el del escrito, sirve para sembrar, despertar experiencias, transformar al lector hacia una sintonía con el narrador, ya que su verdad no puede, no debe ser, solo suya. Inciarte pretende que cabe reconocer algo universal en lo vivido particular, limitado: que lo subjetivo lleva consigo lo objetivo (y viceversa).

6 "Aparte de algún que otro destello de mejor o peor gusto, el libro no destaca más que por lo deslavazado de su contenido. Uno no sabe bien si eso se debe a la incapacidad de su autor de seguir un hilo conductor medianamente coherente o simplemente a un incontrolado deseo de tomarse en broma las cosas más serias de la vida, empezando por la muerte" (Inciarte, 1998: $50)$. 
Sin duda, nuestro autor piensa y también suscita narrativamente una experiencia de verdad. ¿Estamos ante una experiencia de verdad a la que no se accede por otros medios? ¿Es la de un escrito confesional? No exactamente, diría Inciarte:

Más que un relato, el libro es un tratado de metafísica en forma de relato, pero de relato en progresivo estado de deterioro; un deterioro, sin embargo, que ya venía dado desde el principio (Inciarte, 1998: 58).

Un lector de Proust como lo era Inciarte, comparte con él la idea de que la verdad es lo menos obvio, requiere ser descubierta y descifrada. En el Tiempo recobrado, el último de los volúmenes de $A$ la Recherche, se lee:

Las verdades que la inteligencia capta con toda claridad en el mundo de la luz plena tienen algo de menos profundo, de menos necesario que las que la vida nos ha comunicado sin buscarlo nosotros en una impresión (Proust, 1981: 226).

Esa profundidad y necesidad se corresponden con dos operaciones intelectuales: interpretar las impresiones como signos de leyes e ideas, pues pensar, "es hacer salir de la penumbra lo que había sentido", para convertirlo en un equivalente espiritual. La verdad, entonces, resulta de una composición de imágenes del pasado e impresiones contemporáneas, el cuadro de conjunto tiene una "inefable proporción de luz y sombras, de relieve y de omisión, de recuerdo y olvido que la memoria o la observación conscientes ignorarán siempre" (Proust, 1981: 227).

La preferencia de Inciarte por detallar sucesos cualesquiera de la vida cotidiana, unos encuentros, sin la pretensión de ofrecer la representación 
cronológica y total de un curso de cosas externo, le acerca a esa idea proustiana de la verdad que nace de la composición vital. Auerbach ofrece la clave de esa selección a menudo irritante: se piensa que es tiempo perdido pretender ser realmente completo dentro de un determinado curso de cosas exterexterno, tratando de obtener por este procedimiento una percepción de lo esencial, y se teme también que así se imponga a la vida y a su tema una ordenación ajena a ellos.

Quien describe desde el principio hasta el final el curso íntegro de una vida humana, o una trabazón de sucesos enclavada dentro de grandes espacios de tiempo, corta y aísla a capricho: en cada momento la vida ya ha comenzado hace tiempo, y en cada momento también prosigue sin interrupción (Auerbach, 1950: 517).

Los verdaderos viajes son en el tiempo y no en el espacio. ¿Por qué regresa a sí mismo un ser humano, por qué lo hace Inciarte? ¿Para quién? ¿Para nosotros? La voz que dirige el Prólogo dice que su autor

...no se cansa de repetir que no escribe por encargo de nadie y que por eso no va a preocuparse excesivamente de observar una estricta objetividad; que se conforma con decir cómo él ve personalmente las cosas de las que habla ("espero que mi narración no pase de parcial"; quiere decir, espero que no sea, aparte de parcial, injusta con nadie). Por lo menos yo, no veo razón para dudar de su sinceridad (Inciarte, Nota preliminar, Pro manuscripto).

Aunque nuestro autor no ofrece una autobiografía ni una confesión, sí busca el rendimiento de verdad de los escritos confesionales. Como san 
Agustín quería hacer la verdad en el corazón (Confesiones, X, 1,1), Inciarte ensaya en este escrito una "conversión”, una filosófica, intelectual. Se sitúa en el horizonte de la "verdad práctica". A este rasgo diferencial de los escritos confesionales, aunque no exclusivo de ellos, se refiere también Ferraris cuando afirma:

...la verdad no existe en una quieta evidencia contemplativa, se hace presente con un acto ejecutado, se le pone en acción [...] la verdad es, para ser precisos, un acto, incluso como acto público y testamento, que se refiere al otro que hace la verdad en cuanto que es testimonio (Ferraris, 2000: 79) ${ }^{7}$.

Esto es ensayar la resolución de lo subjetivo en lo objetivo y viceversa, que tanto afana a nuestro autor. Porque en relación con las coordenadas de subjetividad y objetividad que articulan esta obra monumental (y no es casual que se hagan evidentes en la parte final, en Cultura y verdad) afirma Inciarte: "yo nunca llegué a conocer al autor". Piensa que esto, desde el punto de vista de la subjetividad,

...puede ser un inconveniente; pero desde el punto de vista de la objetividad, eso mismo puede ser también una ventaja. El ideal de objetividad corre, es cierto, el peligro de caer en falsas idealizaciones. Y sin embargo, también la idealización (esto es, la narración) tiene sus ventajas. Los cortes que he introducido en el libro, convirtiéndolo en fragmentos, hacen ahora del texto más bien algo así como

${ }^{7}$ Para Rousseau, escritor confesional, como para Hegel y Kierkegaard, regresar a sí mismo no significa encerrarse en una interioridad celosa, sino justamente encontrar una legislación universal donde lo nomotético viene a ser lo mismo que lo ideográfico” (Ferraris, 2000: 103) 
una pintura "plurifocal", una especie de iconostasis, sin punto de mira subjetivo privilegiado. Eso equivaldría a su vez a una pura objetividad, la cual, sin embargo, también tiene, como decía, sus inconvenientes (Inciarte, Nota preliminar, Pro manuscripto).

\section{Sobre el qué y lo subjetivo}

Si no se trata estrictamente de una confesión exculpatoria, ni de un relato autobiográfico, que es lo que habitualmente ha impulsado este tipo de escritos, ¿qué le mueve en su caso? ¿La cercanía de la muerte, de la propia muerte? A la luz de otros trabajos suyos, diría que el pensamiento de la muerte - próxima o no tanto- agudiza la experiencia del tiempo, de su paso y de la originariedad del inasible ahora, del presente, por otro lado, lo verdaderamente real del tiempo. El tiempo, en definitiva, que es cifra del misterio de la vida y de la muerte. En su artículo "Über das Jetzt" (publicado por primera vez en alemán en 1996 y en español en 2004), se refiere a esta cuestión:

El tiempo originario existe, pero, si se quiere, no con-siste; ex-iste en el sentido de surgir, un surgir, sin embargo, que no es el surgir de nadie, sino puro surgir, y un surgir que es, a la vez, desaparecer: empezar a ser y dejar de ser en el mismo acto" (Inciarte, 2004: 105) ${ }^{8}$.

Que no se trataba de meras especulaciones, alejadas de las preocupaciones vitales lo deja claro en el Prólogo:

\footnotetext{
${ }^{8}$ Inciarte incluyó este trabajo como un capítulo más de su monumental escrito Catalanes.
} 
Objetividad y subjetividad

Durante toda su vida el autor intentó inútilmente desentrañar el misterio del tiempo. Tales intentos eran parte del servicio inútil en que según él consistía la vida: hay que hacerlos, aunque sean inútiles (ver Lucas XVII, 10). En una nota manuscrita que el autor no recogió en esta colección, se lee: "No siendo el tiempo sino su propia ausencia, no es posible verlo cara a cara, como el Libro de Los Números dice que Moisés vió a Dios. Cara a cara sólo será posible ver el tiempo por el revés" (Inciarte, 1998: 49) 9 .

He mencionado ya las dos cartas que esconde nuestro autor en su narración filosófica: la de la muerte (y la vida, que son una sola), y la del tiempo (y quizás sean solo una y la misma carta). Y en esto consiste (si cabe hablar así) en cierto modo el qué de este libro. "Por varias y hasta divertidas que puedan ser las cosas que narra, el relato trata de una sola, de la muerte" (Inciarte, 1998: 57).

Según Rousseau, la génesis de la hominización se reconoce no en el morir en cuanto tal, algo que es común a otros animales, sino en el conocimiento de la muerte, en su imaginación y en el miedo de su anticipación. El potencial de vida que encierra la conciencia de la mortalidad es un factor clave de la narración de Inciarte. Y, sin embargo, aquí nuestro autor no reflexiona científicamente, filosóficamente sobre la muerte: más bien huye de ella acercándose a la vida, y viceversa... y ¿cómo lo hace? tratando de vivir de modo más intenso, más puro. Como cuando nos dice que "en la escritura se trata a la larga de la tensión entre lo escrito y el escribir”.

9 "El tiempo, como la luna, tiene una cara trasera, que nunca vemos, y eso es lo que el texto de Inciarte parece querer aprehender" (Llano, 1998: 47.) 
Lo escrito, el texto propiamente dicho, es un contenido muerto, mientras que el escribir, como parte del contexto, es algo vivo y actual. Tan vivo y actual como lo era el contenido escrito cuando aún no había pasado ni era objeto de recuerdo alguno sino el sujeto de la acción o, mejor, la misma acción (Inciarte, 1998: 56).

En este giro argumentativo, nuestro autor se inclina por la opción a favor del continente en detrimento del contenido, y pareciera alejarse de Proust, ya que

...no es ni en el recuerdo ni es en la ficción artística donde se encuentra la esencia de las cosas, como si sin él o sin ella, sin la remembranza, las cosas quedaran, como cáscaras vacías, en meros hechos. Pero si la esencia viva de las cosas está en su mismo fluir puntualmente presente, entonces ¿por qué rememorarlas, por qué dejar sus recuerdos por escrito? ¿Qué sentido puede tener esto fuera del escribir mismo? (Inciarte, 1998: 56).

Piensa nuestro autor que desde esta perspectiva el texto adquiere una dimensión que no duda en calificar de mística o, desde una perspectiva más subjetiva, si es que despues de todo lo dicho cabe seguir hablando así, de trágica. Pues

Si consiguiéramos superar el recuerdo, „dejar nuestro cuidado entre las azucenas olvidado“, habríamos conseguido dar con lo único que nos podría proporcionar la bienaventuranza; habríamos conseguido, en otras palabras, la felicidad de una plena presencia [...] Pero entonces ya estaríamos muertos (Inciarte, 1998: 56). 
Por si no fuera bastante exigente con este dejar a un lado las alegrías y penas, los afanes y proyectos, los triunfos y fracasos, para que el lector se entregue sin expectativas de un final feliz, insiste:

Dije que el libro trata de una cosa, de la muerte. En realidad no trata ni de eso ni de ninguna otra cosa es una meditatio mortis. Su contenido temático es prácticamente nulo; las mismas ocasiones en que habla de la muerte real son, como ya dije, escasas (Inciarte, 1998: 57).

Si lo que se busca no está en lo recordado como tal, sino en el escribir, en el vivir, incluso como meditatio mortis, es porque la vida no tiene una unidad que podamos reconocer como quien dice en un golpe de vista, no es como si tuviera un contorno: ella es la que da unidad, es acción unificadora, integradora. Es principio de unidad, pues para el viviente la unidad es por así decir, una tarea siempre pendiente.

La unidad vital es ella mismo trasunto del tiempo. Dice nuestro autor de su propia narración que, como hemos visto es más un escribir que algo escrito:

De todos modos, cuanto más avanza el relato, el punto de gravedad pasa paulatinamente de la dimensión espacial (escritura, cuadernos) a la temporal. Pero entonces el tiempo va perdiendo cada vez más su espacialidad lineal extendida entre el pasado y el presente, hasta convertirse - si eso fuera posible - en un puro presente instantáneo (Inciarte, Nota preliminar, Pro manuscripto). 
Lo que sea o lo que seamos se juega tanto fuera de nosotros (en la cultura, la tradición) como dentro, en los encuentros fugaces y en los sueños. Así pues, estos escritos (como he indicado ya, Catalanes se compone de textos de diversa índole) significan un regreso a sí mismo no solo a vivencias, acontecimientos, trabajos en los que uno ha vivido; al que fue pero ya no es, al menos ya no es tal como era entonces. Inciarte, al igual que Proust, trata de recuperar lo vivido, el tiempo extendido y detenido a la vez; es decir, no tanto empeñarse en apresar lo inasible, como traer el ahora del puro presente instantáneo que, sin embargo, se escapa para poder seguir siendo presente; lo que ya había designado con una metáfora: el Mar Rojo de canto ${ }^{10}$. En El tiempo recobrado Proust se refiere a una experiencia semejante:

Me producía un sentimiento de fatiga percibir que todo aquel tiempo tan largo, había sido vivido, pensado, segregado por mí sin una sola interrupción, sentir que era mi vida, que era yo mismo. [...] Sentir que tenía que mantenerlo cada minuto amarrado a mí, que me sostenía, encaramado yo en su cima vertiginosa, que no

10 "E1 surgir y el desaparecer ocurren realmente. (...) Pero eso no quita para que sólo haya un ahora. Al contrario, lo implica. Si no, estaríamos de nuevo negando o bien que el surgir y - en este caso, sobre todo- el desaparecer sean reales o bien que el surgir y el desaparecer se den en el mismo instante, el simbolizado por el Mar Rojo de canto. Alguien podría objetar: pero si se dan en el mismo instante, entonces el surgir y el desaparecer no se distinguen realmente (...). Lo que esta última objeción deja de lado es la peculiaridad de la continuidad temporal. Esa peculiaridad reside precisamente en el hecho de que en ella no queda nada: el estado presente no menos o no más que el pasado. Con otras palabras, la objeción representa una, otra, recaída en el error de considerar la línea recta como una imagen adecuada del tiempo" (Inciarte, 2004: 116). 
podía moverme sin moverlo. La fecha en que yo oía el sonido de la campanilla del jardín de Combray, tan distante y sin embargo interior, era un punto de referencia en esta dimensión enorme que yo no me conocía. Me daba vértigo ver tantos años debajo de mí, aunque en mí, como si yo no tuviera leguas de estatura (Proust, 1981, 421).

"Que no podía moverme sin moverlo" es el oxímoron de Proust que apunta como el de Inciarte a la misma condición aporética del tiempo real. Pero a este oxímoron del tiempo detenido y extendido se añade otro que es igualmente clave para entender el qué de Cultura y verdad. Lo encontramos en el Prólogo cuando al referirse al contenido dice que, al tratar de la muerte, trata también de la resurrección. Sabemos de ambas "en carne propia", por así decir, mientras vivimos. Aunque sean ficticias según su sentido directo, muerte y resurrección nos acompañan, por ejemplo:

...cuando fracasamos y salimos regenerados del fracaso, o cuando sufrimos y sacamos fuerzas de flaqueza; o cuando se nos olvida y se nos vuelve a recordar; o cuando somos nosotros mismos los que olvidamos y volvemos a recordar, etc. (Inciarte, 1998: 57).

Estas líneas tienen mucho que ver con las coordenadas subjetividad y objetividad, es decir, con "la tensión entre la subjetividad espontánea de los actores, agentes o actuantes en la narración, y la objetividad a la que estos mismos, en cuanto seres racionales y morales, no podían por menos de aspirar" (Inciarte, Nota preliminar). Pues, sin duda se trata de aclararse con uno mismo, sobre uno mismo; y, al mismo tiempo, eso es lo de menos. Hay un 
contenido, un qué cuya adquisición significa una sensibilidad, otra sensibilidad, esto es, un cómo. Casi podría decirse que solo consiste en eso, como en cierto modo es cada acto de conciencia, la conciencia misma que siempre es otro estado.

Hacia ello nos encamina claramente en la primera parte de Cultura y verdad ("Qué y cómo o sobre el objetivismo y subjetivismo en el arte, y su relación con diversas formas de vida"); el autor casi nos desvela la plantilla sobre la que escribe y nos facilita la interpretación que espera que hagamos como lectores atentos. Es la vida, el vivir, lo que estaría en juego, también para los posibles lectores. ¿Es el cómo o es el qué? ¿Es lo subjetivo o lo objetivo? ¿No serían más bien indistintamente uno y otro? De ambas coordenadas, piensa que la de la subjetividad es también aquí la más importante, pero en este caso, a la vez, la más problemática. Siempre lo es, añado yo. Incluso cuando se pretende un trabajo, un escrito estrictamente objetivo.

Así pues, objetividad y subjetividad se confunden en Cultura y verdad como si de una cinta de Moebius se tratara. Pero, como lo difícil no es mostrar que pasamos de una a otra sino dar cuenta de cómo advertimos la diferencia, Inciarte trata de bajar a tierra y revivir la experiencia de ese diferenciar que asume sin anular lo objetivo en lo subjetivo y viceversa. Si "la unidad no le viene al libro tanto por la parte de su contenido como por la de la forma u horma continente", es porque, el "qué" es, sobre todo, un “cómo". Es más contexto que texto:

Así como la objetividad de cualquier libro va unida al contenido de las ideas (filosóficas o no) expuestas en él, la subjetividad tiene evidentemente más que ver 
con el que abriga tales ideas y, en este sentido, tiene que ver también más con la horma material (por ejemplo, emocional) que con el contenido ideal, más con el contexto que con el texto (Inciarte, Nota preliminar, Pro manuscripto).

Inciarte desconfía de la lucidez tan alentada por la filosofía moderna, pero por eso mismo es el más moderno de los modernos. Se precia de que esta narración filosófica tenga algo de subjetivo precisamente para poder proceder con una objetividad no meramente supuesta. Porque meramente supuesta sería una objetividad del tipo de aquélla que pretendía la Ilustración; la dimensión histórica de la verdad era tenida en cuenta sólo como el continuo avance precisamente en dirección a una objetividad alcanzable de una vez para siempre. De ese sueño nos liberó, históricamente hablando, el romanticismo; que nos vino a decir que la verdad no tiene sólo una dimensión objetiva, ahistórica y atemporal, sino también una subjetiva, histórica y temporal; dicho de otra manera: que nos vino a decir que la verdad no es sólo referencial ni sólo predicativa sino también expresiva.

En ese entrecruzamiento de objetividad y subjetividad, según Inciarte, se juega también la suerte de la metafísica y no únicamente la de otras disciplinas filosóficas. Ajeno a las separaciones de las especialidades filosóficas habituales en los trabajos académicos piensa que si "el problema es el de saber cómo dar con una realidad que no es del todo tal, que no es realidad sin más” (Inciarte, 1998: 57). En Catalanes propone una respuesta —dada, por otra parte, ya por Platón- a saber:

...que para dar con una realidad que no lo es del todo, uno no puede por menos de recurrir, por lo menos en parte, a la ficción. Por eso, en vez de considerar co- 
mo otros que los filósofos no son más que poetas fallidos, el autor considera más bien los sistemas filosóficos como grandiosos poemas en los que el predominio de la verdad, de la ficción o, directamente, del error es, en principio, sólo cuestión de grado (Inciarte, 1998: 57).

De aquí se sigue no solo la legitimidad del "relato metafísico" (la horma) que le ocupó a lo largo de la última década de su vida, sino que con frecuencia lo narrado, el contenido, lo extraiga del arte. Piensa Inciarte que la cuestión de qué y el cómo, de la objetividad y subjetividad, comparece como su condición de posibilidad en el arte (Inciarte, 2016: 60-115). "En el límite (mortal, pues,) entre tiempo y eternidad, sucesión y simultaneidad está el arte, a medio camino entre ambas, a las que sintetiza" (Inciarte, Nota preliminar).

Donde se ha despejado una grieta por donde pueda vislumbrarse ese puro presente hasta hacerla andadera es en el arte. Casi podríamos decir en pasado, que la encontró siempre en el arte, como queda probado hasta en sus trabajos más "científicos", los que se consideran estrictamente objetivos, en los que tantas veces una obra de arte forma parte de las respuestas y argumentos y no es traída como mera ilustración de ideas. Pensaba que si lo más característico del arte del siglo XX es que es "presentativo" y metafísica y presencia van siempre unidas, la obra de arte,

...al no representar nada, nos pone de algún modo ante la nada [...] Lo que el arte de nuestro siglo nos ofrece bien podría ser algo parecido a lo que yo intento, no en la filosofía, sino en la filosofía del tipo que dije antes. Ceñirse a su valor de verosimilitud no es despreciar la verdad: es buscar una relación más viva con ella. 
Solo desviando un poco la mirada de un gusano de luz se lo puede ver en la noche (Inciarte, 2001:163-4).

En su narración, el arte opera "como una síntesis de espacio y de tiempo, tiempo y simultaneidad, tiempo y eternidad" (Inciarte, Nota preliminar, Pro manuscripto). Así, lo que en pintura se ha ensayado, a saber, "una vía media entre pura subjetividad y pura objetividad, subjetivismo y objetivismo, como la de una pintura monofocal, que sigue la perspectiva central, pero en la que aún quedaran, sin embargo, restos de plurifocalidad", mucho antes Platón lo "ideó y puso en práctica en las introducciones de muchos de sus diálogos: a encuadramientos dentro de encuadramientos o cuadros dentro de cuadros" (Inciarte, Nota preliminar, Pro manuscripto). Igualmente su relato filosófico consiste en sucesivos encuadramientos. Pero, piensa nuestro autor, que el encuadramiento dentro de otros encuadramientos, (pone como ejemplo Las Meninas, también Las Hilanderas), dentro de un cuadro, es decir, los otros cuadros son sólo eso, fragmentos, pero fragmentos integrados en un conjunto unitario más amplio. Es fácil ver aquí una razón del subtítulo que dio a su "monumental obra": fragmentos de un libro escrito por escribir.

Inciarte admira la genialidad de Velázquez que modifica el canon tradicional al presentar el arte no como un producto, sino como el proceso de su propia producción.

El último enmarcamiento no es, según esto, el señalado por el marco del cuadro, sino el del pintor pintándolo. Que éste no aparezca, como en Las Meninas, en el lienzo es aquí secundario. De un modo o de otro, el último contexto o encuadramiento del arte, la vida, es fundamentalmente inasible. Esto relativiza la 
importancia de cualquier texto (pictórico, narrativo o del tipo que sea) que, como el del presente libro, trate de captar su propio contexto. Y eso mismo justifica, para decirlo de una vez, la desaprensión con que me he permitido reducirlo casi a una colección multifocal de fragmentos en los que las personas y cosas involucradas aparecen, si no completamente objetivadas, sí en cierta medida "dessubjetivadas"; quiero decir: más desasistidas de su contexto real de lo que ya quedaban en la relativa fragmentación de la versión original. Esta su - por decirlo así- re-contextualización modifica, por supuesto, el texto. Pero también eso puede ser una ventaja, igual que Marcel Duchamp dió la vuelta a un urinario que se encontró por ahí para convertirlo en una fontana digna de los honores de un museo. El qué seguía siendo en esos casos el mismo. Pero de lo que se trata siempre, en arte más aún que en la vida, es del cómo. Del cómo y del dónde. Del contexto (Inciarte, Nota preliminar, Pro manuscripto).

A lo largo de las recenciones y prólogos, como en los capítulos que componen Cultura y verdad, Inciarte muestra una preocupación por la unidad, por la unidad del libro: no la tiene sin más. Es la misma que la de la unidad de la vida. Como esta, la del libro se va haciendo y deshaciendo mientras se vive, es siempre otra. Por eso tal vez la escritura sobre los prólogos, la selección de fragmentos...

La unidad de este libro, su cómo y qué, reside justamente en su nulidad temática, que se da como una progresiva anulación-purificación de todo contenido. De golpe solo se alcanza en la muerte. Le dejo hablar a él, cuando en la misma recensión añade:

La unidad del libro está más allá de él y más allá de la vida que el autor todavía vivía cuando lo estaba escribiendo. En su misma falta de plenitud, el libro es un 
símbolo de la realidad de este mundo tal y como el autor la veía. Con esto queda dicho que, más que un relato, el libro es un tratado de metafísica en forma de relato, pero de relato en progresivo estado de deterioro; un deterioro, sin embargo, que ya venía dado desde el principio. El relato se podría haber acabado, en efecto, en cualquier momento, igual que la vida — por falta de papel o por lo que fuere. Nada, o poco, hubiera cambiado entonces sustancialmente, puesto que todo pende siempre del hilo de la casualidad, por ejemplo, del papel disponible (Inciarte, 1998: 57-8).

Comenzaba este artículo haciendo referencia a la actual exigencia de verdad y realidad. Inciarte entendió que precisamente por su condición insustituible, no procede esperar pasivamente que llegue desde fuera. A lo largo de todo su trabajo y, de manera excepcional en las páginas publicadas como Cultura y verdad, encontramos las evidencias de su empeño constante por lograr la relación más viva posible con la verdad. Hasta su último aliento.

\section{Bibliografia}

E. Auerbach, Mimesis. México, Fondo de Cultura Económica, 1950.

R. Barthes, El placer del texto, Madrid, Siglo XXI, 2007.

M. Ferraris, Luto y autobiografía. De san Agustin a Heidegger, Madrid, Taurus, 2000.

D. Hume, Ensayos morales, politicos y literarios (trad. C. Martínez Ramírez), Taurus, Trotta, 2011.

F. Inciarte, "Prólogo a Catalanes, un libro escrito por escribir", Nueva Revista, 1998 (58), 48-63.

-, Breve Teoría de la España moderna, Pamplona, Eunsa, 2001.

—, Cultura y verdad (Ed. L. Flamarique), Pamplona, Eunsa, 2016. 


\section{Lourdes Flamarique}

—, "Nota preliminar", Catalanes. Fragmentos de un libro escrito por escribir, Pro manuscripto.

—, "Sobre el ahora", Tiempo, sustancia, lenguaje. Ensayos de metafísica (Ed. L. Flamarique). Pamplona, Eunsa, 2004.

R. Llano, "Fernando Inciarte: la Filosofía como relato", Nueva Revista, 1998 (58), 44-47.

M. Proust, En busca del tiempo perdido. El tiempo recobrado, Madrid, Alianza Editorial, 1981.

S. Žižek, Bienvenidos al desierto de lo real, Madrid, Akal, 2005.

L. Wittgenstein, Observaciones sobre los fundamentos de la matemática, Madrid, Alianza Universidad, 1987.

Lourdes Flamarique

lflamarique@unav.es 